\title{
Time-Domain Characterization of Dual Band Spiral Antenna with WMTS/UWB Application
}

\author{
Saira Joseph, ${ }^{1}$ Sunil Jacob, ${ }^{1}$ Binu Paul, ${ }^{2}$ Shanta Mridula, ${ }^{2}$ and Pezholil Mohanan ${ }^{3}$ \\ ${ }^{1}$ Electronics and Communication Engineering Department, SCMS School of Engineering and Technology, Cochin, India \\ ${ }^{2}$ Division of Electronics Engineering, School of Engineering, CUSAT, Cochin, India \\ ${ }^{3}$ Department of Electronics, CUSAT, Cochin, India \\ Correspondence should be addressed to Sunil Jacob; suniljacob@scmsgroup.org
}

Received 10 January 2017; Accepted 19 February 2017; Published 12 March 2017

Academic Editor: Shih Yuan Chen

Copyright (c) 2017 Saira Joseph et al. This is an open access article distributed under the Creative Commons Attribution License, which permits unrestricted use, distribution, and reproduction in any medium, provided the original work is properly cited.

\begin{abstract}
A coplanar waveguide- (CPW-) fed spiral antenna with dual band application is presented. The antenna is designed to operate over the UWB (3.1-10.6 GHz) band as well as in a lower band suitable for WMTS (1.395-1.4 GHz). Frequency domain characterization shows that the antenna is well matched with appreciable gain in both bands. Time-domain studies are carried out to check the suitability of the antenna in pulsed communication. A prototype of the antenna is fabricated and measured results show low group delay variation in the UWB. FWHM and ringing of antenna impulse response, fidelity factor, and radiated power spectral density are also presented.
\end{abstract}

\section{Introduction}

Over the past decade, there is a great demand for permission to transmit large bandwidth concurrent with existing narrowband signals. In 2002, the FCC decided to permit use of Ultrawide Band (UWB) systems. UWB systems are unique in their large instantaneous bandwidth from 3.1 to $10.6 \mathrm{GHz}$ and potential for low-cost digital design that enables a single system to operate in different modes as a communications device, radar, and so forth. The addition of more and more features in each new generation communication system demands universal antennas suitable for operation in multiple bands. In this regard, designing a multiband antenna which also covers the UWB range is of high interest [1-3]. Typically, narrowband antennas are described in the frequency domain. But UWB systems are often realized in an impulse-based technology, and therefore the time-domain effects and properties have to be known as well.

In [4], a spanner-shaped UWB antenna with meandered strip is presented for integrated GSM 1800/Bluetooth operation. A PIN diode is used as a switch to control the length of the meandered strip to obtain desired lower band operation. In [5], a UWB slot antenna with three additional lower bands suitable for GPS, GSM, and Bluetooth operation is developed using inverted $\mathrm{U}$-shaped strips. The antenna is compact, but gain is very low at the lower bands. In [6], also, a highly compact UWB antenna incorporating GPS, GSM, and WLAN bands is presented. However, in all antennas, time-domain studies are limited to the evaluation of group delay only. The antenna effects on the signal transmission needs to be analyzed by considering the envelope of the transient response. The transient response can be measured by direct time-domain measurements or by a frequency domain measurement followed by Fourier Transformation [7].

This paper presents time-domain characterization of a coplanar waveguide- (CPW-) fed spiral antenna for dual band operation. CPW-feed technique is a popular choice due to its inherent properties such as wide bandwidth [8], ease of integration with monolithic microwave integrated circuits (MMICs), and compact size. The orientation of the spiral monopole with respect to the $\mathrm{CPW}$-feed line is such that its outermost turn is similar to the periphery of a simple circular monopole. This results in UWB operation. The turns of the spiral behave as a ring resonator and, by introducing shorting strips between the arms of the spiral, a lower band with operation frequency suitable for Wireless Mobile Telecommunication Services (WMTS) is also obtained resulting in 


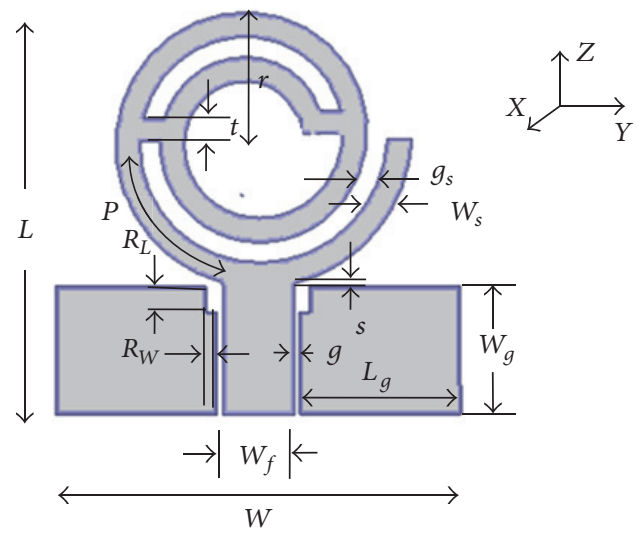

FIgURE 1: Geometry of the proposed antenna.

dual band operation. The antenna is designed on Rogers substrate of relative permittivity 2.2 and thickness $0.79 \mathrm{~mm}$ and since it operates in UWB application band emphasis is given to time-domain characteristics. Simulation studies are carried out using Ansys HFSS ${ }^{\text {тм }}$ software and are in good agreement with measured results.

\section{Antenna Geometry and Frequency Domain Experimental Results}

The antenna is printed on a substrate of relative permittivity $\epsilon_{r}=2.2$ and thickness $h=0.79 \mathrm{~mm}$. The spiral consists of two complete turns of metal strips of width $W_{s}$ with uniform spacing $g_{s}$ between the turns. The CPW-feed line is designed for $50 \Omega$ impedance with width $W_{f}$ with spacing $g$ from the ground plane. The truncated ground on either side of the feed line is of length $L_{g}$ and width $W_{g}$. The monopole has a spacing $s$ from the ground plane and the overall size of the antenna is $38.6 \times 38 \mathrm{~mm}^{2}$. The geometry of the proposed antenna is shown in Figure 1.

A small section of the ground plane of size $R_{W} \times R_{L}$ is cut away near the feed line to improve matching at higher frequencies. The spiral is asymmetrically oriented with respect to the feed line such that its outermost turn with radius $r$ mimics the outer edge of a simple circular monopole [9] and results in UWB operation. The length of the longer arm of the spiral monopole is designed using the regression equation

$$
\mathrm{SL} \approx-28.12 f_{1}-6.02 \epsilon_{r}-1.91 h+178.43,
$$

where $f_{1}$ is the resonance frequency of the lower band.

The spiral monopole with two shorting strips between its turns results in a lower band suitable for WMTS application. One strip is placed at a distance $P$ along the length of the spiral monopole from feed line and it has a width $t$. The position of this shorting strip determines the resonance frequency of the lower band. This is evident from the current distribution shown in Figure 2.

At $1.4 \mathrm{GHz}$, the current distribution shows that the shorting strip alters the flow of current on the outer turn of the spiral. The path created by the shorting strip creates a quarter wave distribution along the lower portion of the inner turn and results in linear polarization. By placing a second shorting strip of the same width at the inner end of the spiral, improved impedance matching is obtained in the UWB without disturbing the first resonance. The optimized design parameters of the antenna are $W=38.6 \mathrm{~mm}, L=$ $38 \mathrm{~mm}, L_{g}=12.3 \mathrm{~mm}, W_{g}=15.4 \mathrm{~mm}, R_{L}=2.6 \mathrm{~mm}, R_{W}=$ $1 \mathrm{~mm}, W_{f}=6.9 \mathrm{~mm}, g=0.48 \mathrm{~mm}, s=0.48 \mathrm{~mm}, g_{s}=1.83 \mathrm{~mm}$, $W_{s}=2.44 \mathrm{~mm}, r=13 \mathrm{~mm}, P=17 \mathrm{~mm}$, and $t=2.44 \mathrm{~mm}$. A prototype of the antenna is fabricated on Rogers RT/duroid 5880 substrate and tested using Agilent PNA 8362B network analyzer.

Measured reflection characteristics are compared with simulation results and shown in Figure 3. Simulated and measured values are in good agreement. There is a mismatch in readings at higher frequencies but this can be attributed to soldering effects that have not been accounted for in simulation studies. The antenna operating frequency ranges are $1.35-1.52 \mathrm{GHz}$ and $3.1-11 \mathrm{GHz}$ for $S_{11} \leq-10 \mathrm{~dB}$. Though the antenna exhibits sufficient impedance matching at the intended operating frequencies, it is important to have sufficient gain and stable radiation patterns.

At first resonance and lower frequencies of the UWB, a doughnut pattern is observed in the $X-Z$ plane with almost nondirectional pattern in the $X-Y$ plane. At upper end of the $\mathrm{UWB}$, the pattern is slightly distorted due to the excitation of higher order modes in the monopole but still has nearly nondirectional characteristics in $X-Y$ plane throughout the operating range.

The peak gain measured using two-antenna method [10] is shown in Figure 4.

The antenna has a peak gain of $7.5 \mathrm{dBi}$ at $1.4 \mathrm{GHz}$. Within the UWB range, gain is steady with a peak value of $5.2 \mathrm{dBi}$.

\section{Time-Domain Characterization}

In UWB systems used for impulse radio, a series of unmodulated pulses are used for communication and each pulse carries one symbol of information. The pulse input to the antenna system has an extremely large bandwidth and, hence, any variation in group delay across the passband of the transmitted pulse is likely to distort the pulse. A nondistorting antenna geometry is characterized by a constant group delay [11]. To evaluate the group delay, two antennas with identical radiation characteristics are placed $15 \mathrm{~cm}$ apart in three different orientations: face to face, face to side, and side to side and measured results are shown in Figure 5.

Group delay variation for face-to-face and face-to-side orientations is within an acceptable limit of $1 \mathrm{~ns}$. In sideto-side orientation the group delay variation occasionally exceeds 2 ns.

In order to evaluate transient response of the antenna, first frequency domain measurements are done by modeling the antennas as a Linear Time Invariant (LTI) system. A pair of the antennas under test are placed ensuring that they are separated by far field distance $R$ corresponding to the lowest frequency of operation as shown in Figure 6. 

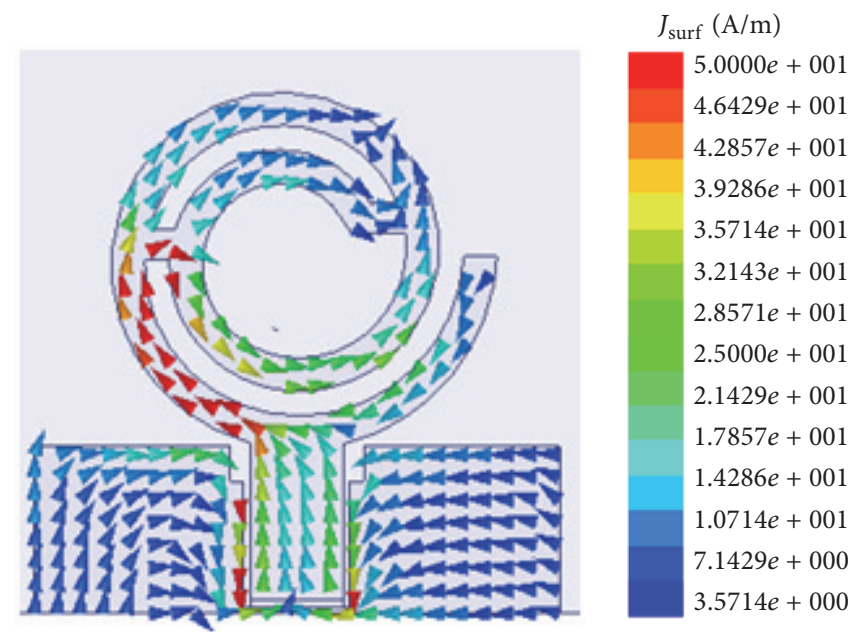

FiguRE 2: Current distribution of the proposed antenna at $1.4 \mathrm{GHz}$.

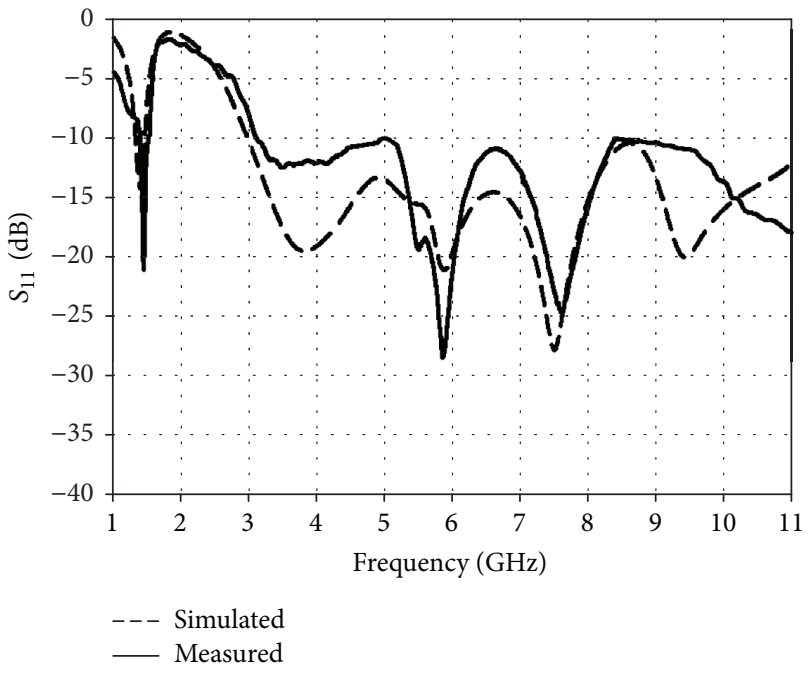

FIGURE 3: Measured and simulated reflection characteristics of the proposed antenna.

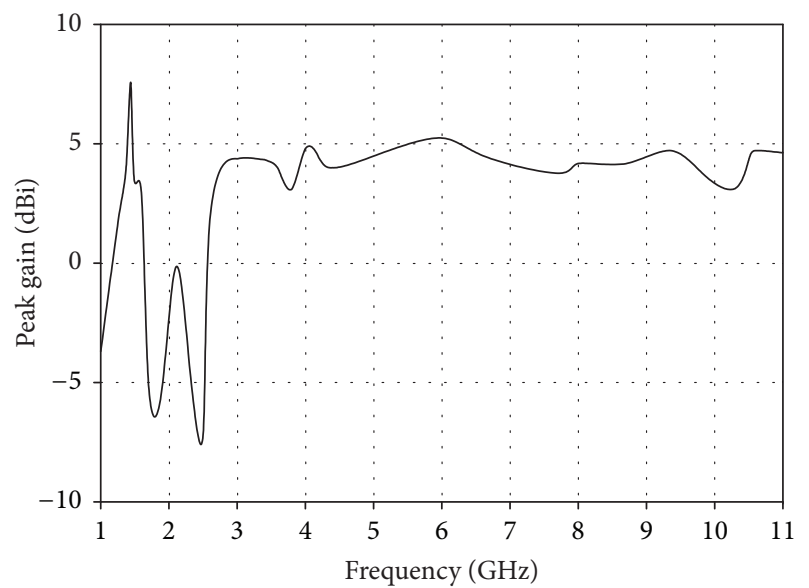

FIGURE 4: Measured peak gain of the proposed antenna.

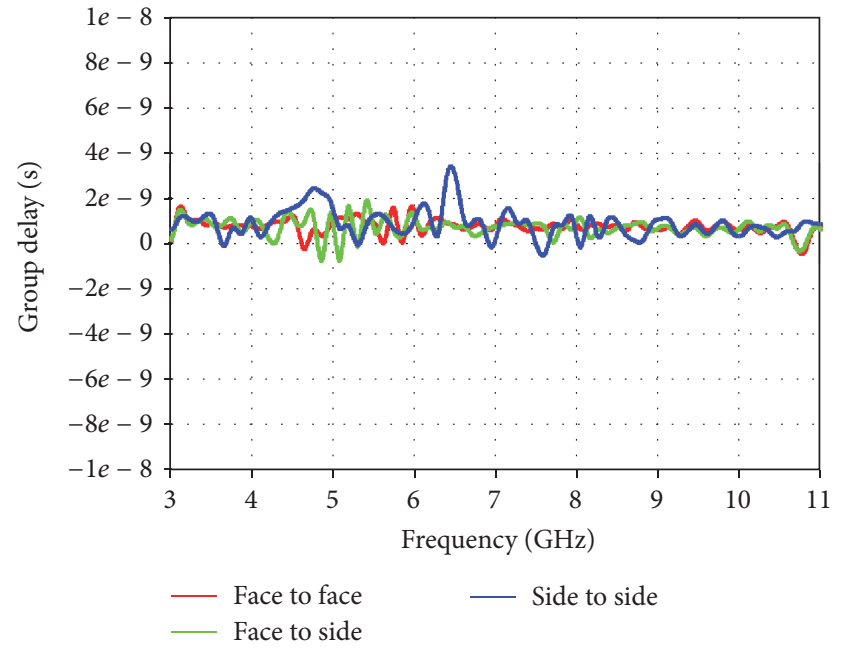

FIGURE 5: Measured group delay of the proposed antenna for different orientations.

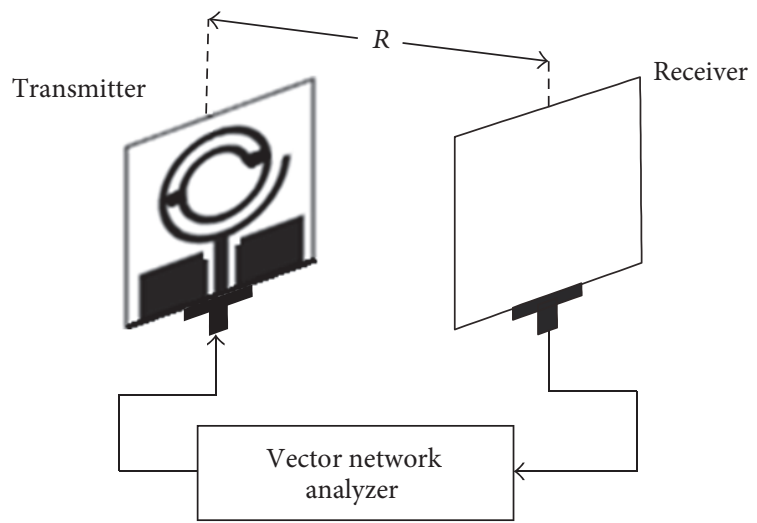

FIgURE 6: Measurement setup for time-domain response. 


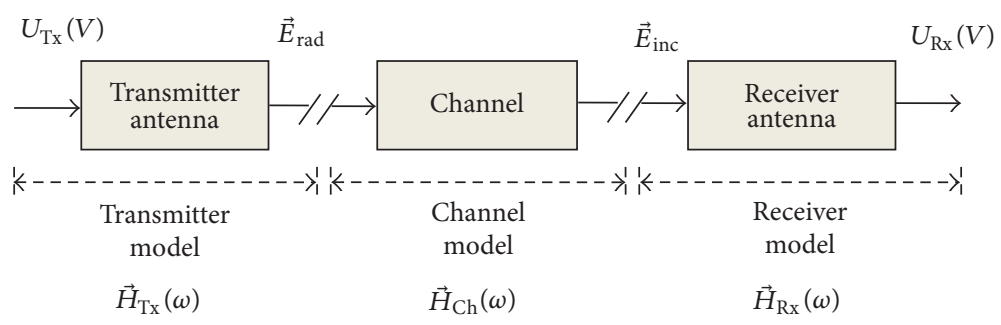

Figure 7: UWB system channel model.

One antenna is used as a transmitter while the other antenna is used as receiver. This UWB channel can be modeled as shown in Figure 7.

The frequency domain relation between received voltage pulse $U_{\mathrm{Rx}}(\omega, r, \theta, \varphi)$ and incident electric field pulse $\vec{E}_{\mathrm{rad}}(\omega, r, \theta, \varphi)[7]$ is

$$
\frac{U_{\mathrm{Rx}}(\omega, r, \theta, \varphi)}{\sqrt{z_{c}}}=\vec{H}_{\mathrm{Rx}}(\omega, \theta, \varphi) \frac{\vec{E}_{\mathrm{rad}}(\omega, r, \theta, \varphi)}{\sqrt{z_{0}}},
$$

where $z_{c}$ and $z_{0}$ are characteristic impedance of the antenna port and free space. The transfer function of the receiving antenna $\vec{H}_{\mathrm{Rx}}(\omega, \theta, \varphi)$ is a function of the direction of arrival of the incident field pulse.

The frequency domain relation between transmitted electric field pulse $\vec{E}_{\text {rad }}(\omega, r, \theta, \varphi)$ and incident voltage pulse $U_{\mathrm{Tx}}(\omega, r, \theta, \varphi)$ is

$$
\begin{aligned}
& \frac{\vec{E}_{\mathrm{rad}}(\omega, r, \theta, \varphi)}{\sqrt{z_{0}}} \\
& =\vec{H}_{\mathrm{Tx}}(\omega, \theta, \varphi) \frac{e^{-j \omega(r / c)}}{r} \frac{U_{\mathrm{Tx}}(\omega, r, \theta, \varphi)}{\sqrt{z_{c}}},
\end{aligned}
$$

where $\vec{H}_{\mathrm{Tx}}(\omega, \theta, \varphi)=\frac{j \omega}{2 \pi c} \vec{H}_{\mathrm{Rx}}(\omega, \theta, \varphi)$.

Substituting (3) in (2)

$$
\begin{aligned}
& \frac{U_{\mathrm{Rx}}(\omega, r, \theta, \varphi)}{\sqrt{z_{c}}} \\
& =\vec{H}_{\mathrm{Rx}}(\omega, \theta, \varphi) \vec{H}_{\mathrm{Tx}}(\omega, \theta, \varphi) \frac{e^{-j \omega(r / c)}}{r} \frac{U_{\mathrm{Tx}}(\omega, r, \theta, \varphi)}{\sqrt{z_{c}}} .
\end{aligned}
$$

Now the whole input to output characteristic is given as

$$
\begin{aligned}
S_{21} & =\frac{U_{\mathrm{Rx}}(\omega, r, \theta, \varphi)}{U_{\mathrm{Tx}}(\omega, r, \theta, \varphi)} \\
& =\vec{H}_{\mathrm{Rx}}(\omega, \theta, \varphi) \vec{H}_{\mathrm{Tx}}(\omega, \theta, \varphi) \frac{e^{-j \omega(r / c)}}{r} .
\end{aligned}
$$

Substituting (4) in (6), transfer function of the antenna can be determined from the measured values of $S_{21}$ using the relation

$$
\vec{H}_{\mathrm{Rx}}(\omega, \theta, \varphi)=\sqrt{\frac{2 \pi c r S_{21} e^{j \omega R / c}}{j \omega}},
$$

where $c$ is free space velocity.
TABLE 1: Measured FWHM and ringing of antenna impulse response for varying azimuth angles.

\begin{tabular}{lcc}
\hline Azimuth angle & FWHM (ps) & Ringing (ps) \\
\hline$\Phi=0^{\circ}$ & 202 & 274 \\
$\Phi=45^{\circ}$ & 190 & 267 \\
$\Phi=90^{\circ}$ & 166 & 115 \\
$\Phi=135^{\circ}$ & 220 & 474 \\
$\Phi=180^{\circ}$ & 186 & 131 \\
$\Phi=225^{\circ}$ & 201 & 228 \\
$\Phi=270^{\circ}$ & 161 & 371 \\
$\Phi=315^{\circ}$ & 185 & 436 \\
\hline
\end{tabular}

Measurement is performed for different spatial orientations of the two antennas in azimuth plane. The impulse response of the antenna is obtained by taking the inverse Fourier transform of the transfer function.

The envelope of the impulse response localizes the distribution of energy versus time and hence is a direct measure for the dispersion of an antenna. The envelope width describes the broadening of the radiated impulse and is characterized by the full width of magnitude of the envelope at half maximum (FWHM). The variation in amplitude of the impulse response indicates ringing and the duration of the ringing is defined as the time period over which the envelope has fallen from the peak value to $-13 \mathrm{~dB}$ of the peak. Measured values of FWHM and ringing of the proposed antenna for different azimuth angles are quite low as shown in Table 1.

The FCC constrains the radiated power spectral density of UWB systems to $-41.3 \mathrm{dBm} / \mathrm{MHz}$. In impulse radio, the signal that represents a symbol consists of a pulse with a very low duty cycle. The pulse can be any function which satisfies the spectral mask regulatory requirements. Higher order derivatives of the Gaussian pulse [12] are found to provide a better match to the required emission mask. As the order of the derivative pulse increases, energy moves to higher frequencies. A common choice of the UWB input pulse waveform is the fourth-order Gaussian pulse and is used in the time-domain characterization of the proposed antenna. The pulse is of the form

$$
V_{G}(t)=\left[\frac{12}{\sigma^{4}}+\frac{48}{\sigma^{6}}(t-1)^{2}+\frac{16}{\sigma^{8}}(t-1)^{4}\right] e^{-((t-1) / \sigma)^{2}},
$$

where $\sigma$ is a pulse parameter and is taken to be $67 \mathrm{ps}$ to conform to the FCC limits. 


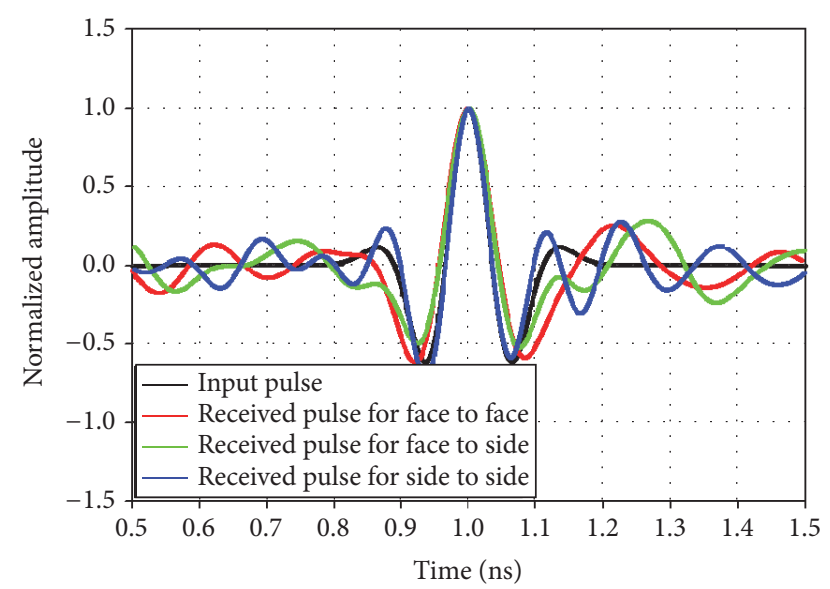

FIGURE 8: Comparison of input and received pulses of the proposed antenna for different orientations.

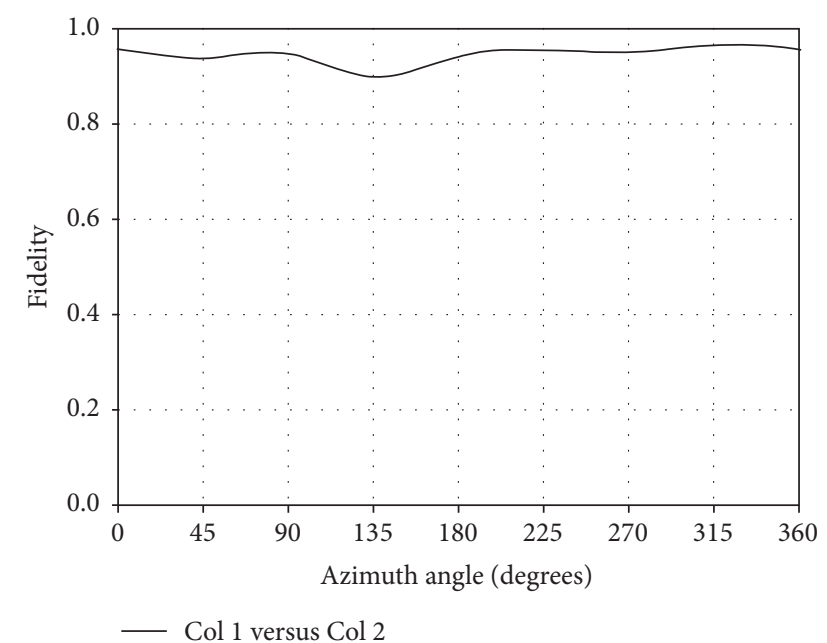

FIGURE 9: Measured fidelity factor of the proposed antenna in azimuth plane.

For a UWB system, the received pulse is required to match the input pulse with minimum distortions because the pulse carries useful information. To examine the time-domain characteristic of the antenna, the incident pulse spectrum is multiplied by the normalized antenna transfer function. Then an inverse Fourier transform is performed to obtain timedomain response of the output waveform at the receiving antenna terminal. The normalized received pulses for three different orientations are shown in Figure 8.

The degree of correlation between the input and received pulses is evaluated using the fidelity factor [13]

$$
\mathrm{FF}=\max \frac{\int s_{i}(t) s_{o}(t-\tau) d \tau}{\sqrt{\int s_{i}^{2}(t) d t \int s_{o}^{2}(t) d t}} .
$$

Fidelity factor values obtained in the azimuth plane are plotted in Figure 9 and they are consistently above 0.9 which shows very good matching between input and received pulses.

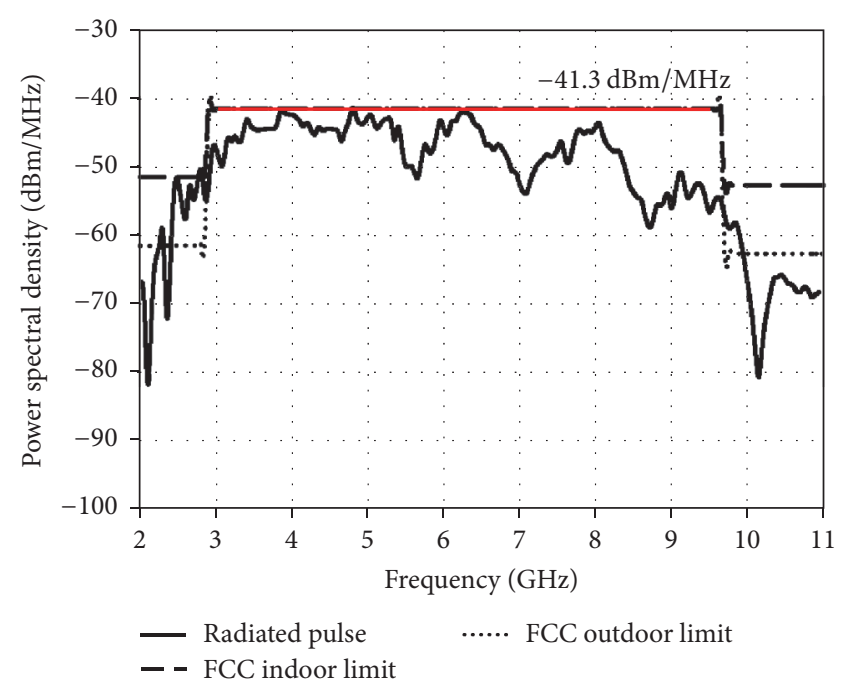

FIGURE 10: Power spectral density of the radiated pulse for the proposed antenna against the FCC emission mask.

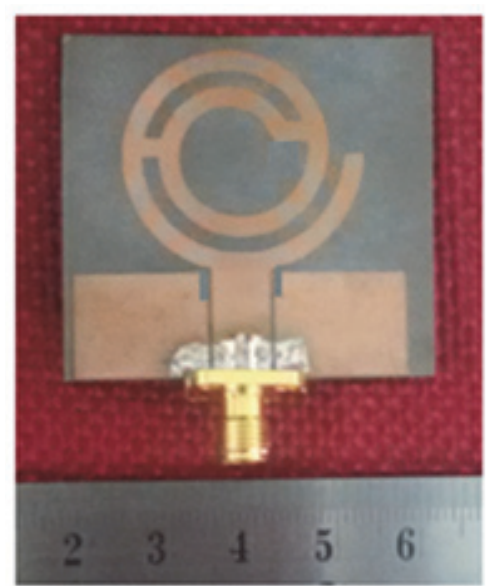

FIgURE 11: Prototype of antenna fabricated on Rogers RT/duroid 5880 substrate.

UWB systems may cause interference to other wireless systems since they operate over a large frequency range, which covers many bands being used. Thus, the emission limit is a crucial consideration for the design of UWB antennas.

According to FCC regulations, UWB systems must comply with stringent emission limits in the frequency band of operation. Radiated power spectral density of the antenna is plotted in Figure 10.

Within the frequency range from 3.1 to $10.6 \mathrm{GHz}$ the radiated power of the proposed antenna is compliant with both the indoor and outdoor limits imposed by the FCC which confirms their suitability for UWB applications. A photograph of the fabricated antenna is shown in Figure 11.

\section{Conclusion}

A compact CPW-fed spiral antenna for dual band applications is presented. The operating bands are suitable for 
WMTS and UWB applications. Good impedance matching and stable gain across the operating bands make the antenna a good candidate for wireless communication devices. To check the suitability of the antenna for pulsed communication in UWB systems, time-domain characterization is also performed. Measured results show that the antenna has low pulse distortion with a fidelity factor consistently above 0.9 in the azimuth plane. The antenna radiated power spectral density is also within the limits specified by FCC.

\section{Conflicts of Interest}

The authors declare that there are no conflicts of interest regarding the publication of this paper.

\section{References}

[1] S. K. Mishra, R. Gupta, A. Vaidya, and J. Mukherjee, "Printed fork shaped dual band monopole antenna for bluetooth and UWB applications with 5.5GHZ WLAN band notched characteristics," Progress In Electromagnetics Research C, vol. 22, pp. 195-210, 2011.

[2] B. S. Yildirim, B. A. Cetiner, G. Roqueta, and L. Jofre, "Integrated Bluetooth and UWB antenna," IEEE Antennas and Wireless Propagation Letters, vol. 8, pp. 149-152, 2009.

[3] Y.-F. Liu, P. Wang, and H. Qin, "Compact ACS-fed UWB monopole antenna with extra Bluetooth band," Electronics Letters, vol. 50, no. 18, pp. 1263-1264, 2014.

[4] S. Naser and N. Dib, "Spanner-shaped ultra-wideband monopole antenna with bluetooth and GSM coverage," Jordan Journal of Electrical Engineering, vol. 2, no. 2, pp. 94-106, 2016.

[5] M. Bod, H. R. Hassani, and M. M. Samadi Taheri, "Compact UWB printed slot antenna with extra bluetooth, GSM, and GPS bands," IEEE Antennas and Wireless Propagation Letters, vol. 11, pp. 531-534, 2012.

[6] A. Foudazi, H. R. Hassani, and S. M. A. Nezhad, "Small UWB planar monopole antenna with added GPS/GSM/WLAN bands," IEEE Transactions on Antennas and Propagation, vol. 60, no. 6, pp. 2987-2992, 2012.

[7] W. Wiesbeck, G. Adamiuk, and C. Sturm, "Basic properties and design principles of UWB antennas," Proceedings of the IEEE, vol. 97, no. 2, pp. 372-385, 2009.

[8] L. Liu, Y. Z. Yin, C. Jie, J. P. Xiong, and Z. Cui, "A compact printed antenna using slot-type CSRR for $5.2 \mathrm{GHz} / 5.8 \mathrm{GHz}$ band-notched UWB application," Microwave and Optical Technology Letters, vol. 50, no. 12, pp. 3239-3242, 2008.

[9] J. Liang, C. C. Chiau, X. Chen, and C. G. Parini, "Study of a printed circular disc monopole antenna for UWB systems," IEEE Transactions on Antennas and Propagation, vol. 53, no. 11, pp. 3500-3504, 2005.

[10] C. A. Balanis, Antenna Theory: Analysis and Design, Wiley India, 2nd edition, 2007.

[11] R. Bazaz, S. K. Koul, M. Kumar, and A. Basu, "An ultrawideband antenna with band reject capability and its characterization in time domain," Progress In Electromagnetics Research C, vol. 19, pp. 223-234, 2011.

[12] M. A. Elmansouri and D. S. Filipovic, "Pulse distortion and mitigation thereof in spiral antenna-based UWB communication systems," IEEE Transactions on Antennas and Propagation, vol. 59, no. 10, pp. 3863-3871, 2011.
[13] A. E.-C. Tan, M. Y.-W. Chia, K. K.-M. Chan, and K. Rambabu, "Modeling the transient radiated and received pulses of ultrawideband antennas," IEEE Transactions on Antennas and Propagation, vol. 61, no. 1, pp. 338-345, 2013. 


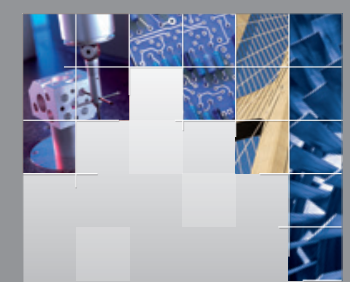

\section{Enfincering}
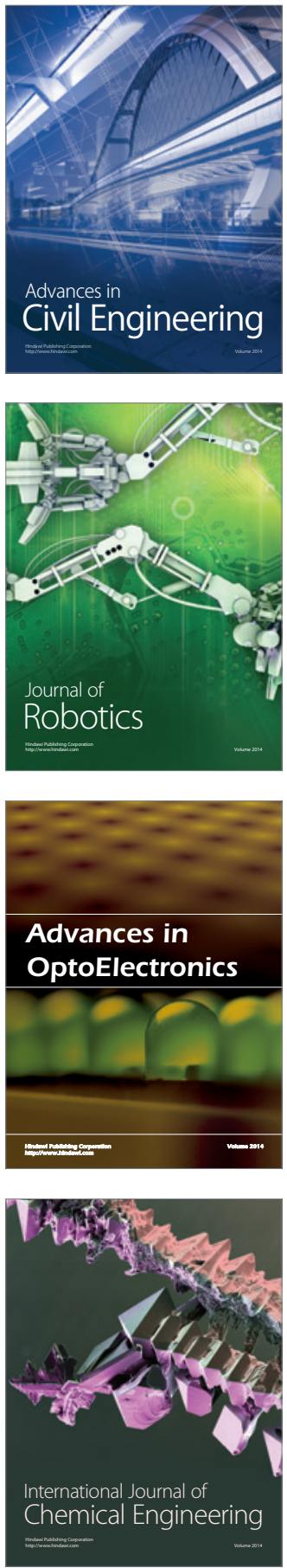

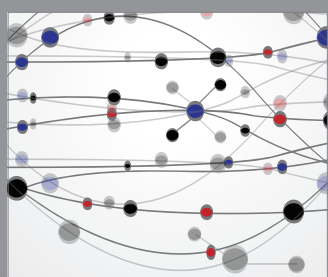

The Scientific World Journal

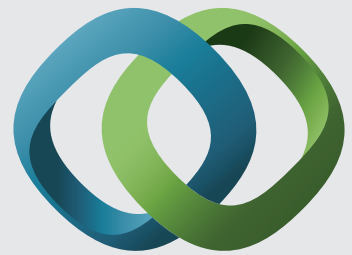

\section{Hindawi}

Submit your manuscripts at

https://www.hindawi.com
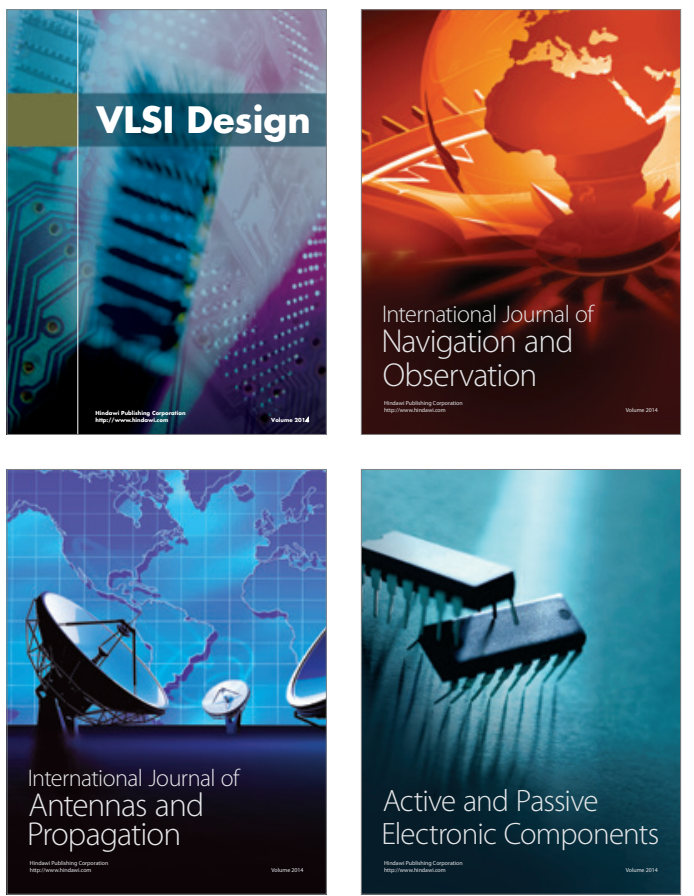
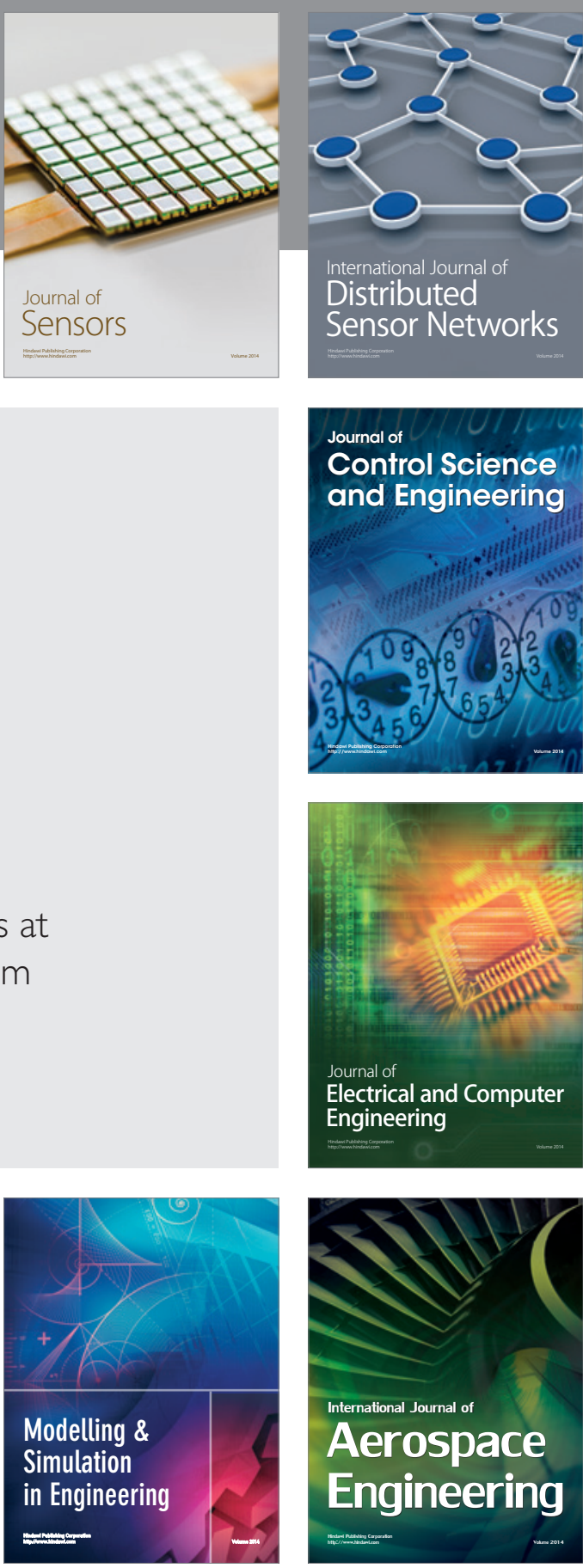

International Journal of

Distributed

Sensor Networks

$-$

Joumal of

Control Science

and Engineering
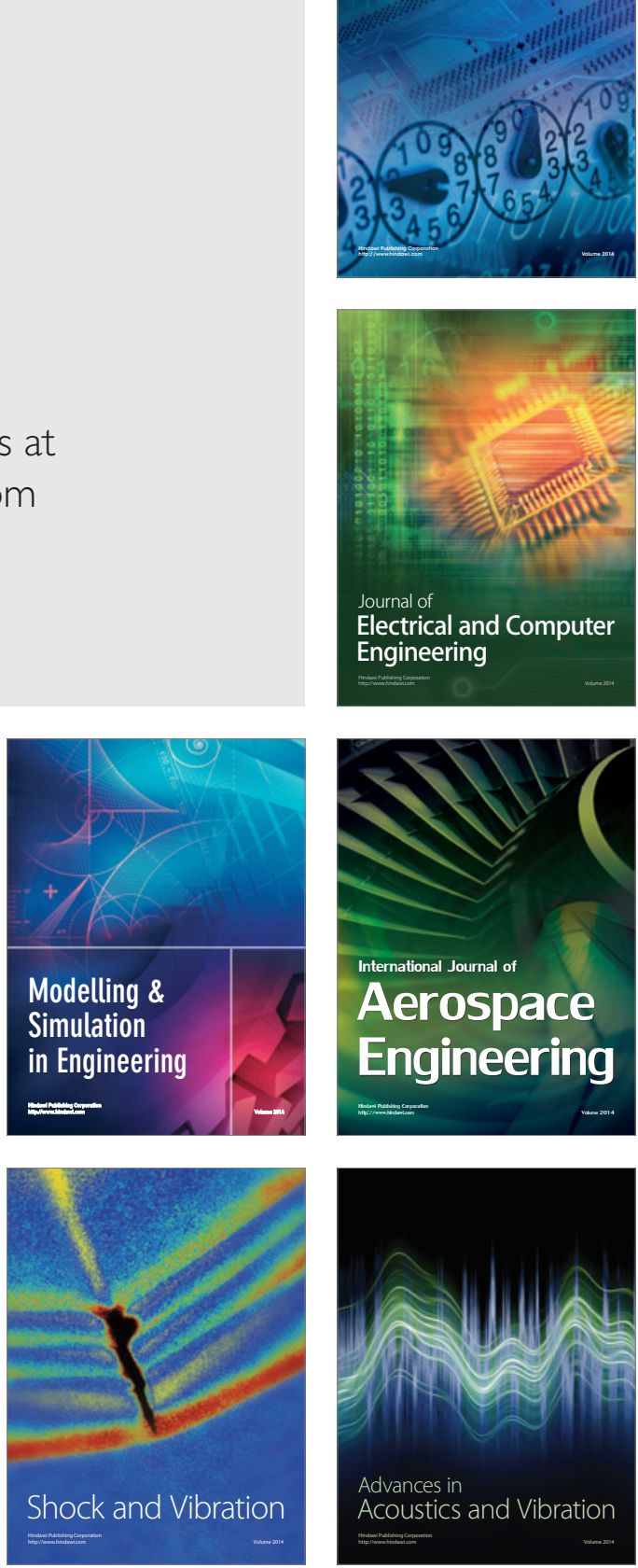